\title{
O PROCESSAMENTO DA NARRATIVA NO ENVELHECIMENTO E SUA RELAÇÃO COM MEMÓRIAS DE TRABALHO E EPISÓDICA E FUNÇÕES EXECUTIVAS
}

Lilian Cristine Scherer

Pontifícia Universidade Católica do Rio Grande do Sul

Aline Elisabete Pereira Universidade de Santa Cruz do Sul

Onici Claro Flôres Universidade de Santa Cruz do Sul

Rosângela Gabriel Universidade de Santa Cruz do Sul

Camila Rosa de Oliveira Pontifícia Universidade Católica do Rio Grande do Sul 
Rochele Paz Fonseca

Pontifícia Universidade Católica do Rio Grande do Sul

\title{
Resumo
}

Em face da importante escassez de estudos sobre processamento do discurso no envelhecimento e do conhecimento ainda restrito quanto à relação dos componentes linguísticos envolvidos na leitura de textos e outros componentes cognitivos, como a memória, o presente estudo teve por objetivo comparar o processamento do texto narrativo entre leitores adultos jovens e leitores adultos idosos. Igualmente, visou investigar se há relação entre esta habilidade leitora e sistemas de memória (episódica e de trabalho). Houve diferenças significativas entre os grupos em termos de acurácia na resolução das tarefas de leitura apenas em uma questão envolvendo coerência extratextual que inclui conhecimento metafórico e cultural, tarefa na qual os adultos jovens apresentaram melhor desempenho. O tempo de resposta dos idosos foi significativamente mais alto nas tarefas de leitura e em alguns testes neuropsicológicos. Além disso, o desempenho dos idosos na comparação com o grupo de adultos jovens foi significativamente mais baixo em alguns itens dos testes que mensuraram a memória de trabalho e episódica.

Palavras-chave: compreensãoleitora; narrativa; envelhecimento; escolaridade; memória episódica; memória de trabalho.

\section{NARRATIVE PROCESSING IN AGING AND ITS RELATION WITH EPISODIC AND WORKING MEMORY AND EXECUTIVE FUNCTIONS}

\begin{abstract}
Considering the lack of studies on discourse processing in aging and our still restricted knowledge about the relationship between linguistic components involved in text reading and other cognitive components, such as memory, the present study aimed to compare narrative processing by young adult readers
\end{abstract}


and elderly readers. Moreover it aimed to investigate whether there is a relationship between this reading ability and memory systems (more specifically episodic and working memory). In terms of accuracy in the resolution of the reading comprehension tasks, there was a statistically significant difference between groups in only one task, which measured extratextual coherence including metaphorical and cultural knowledge, with the young group outperforming the elderly one. Significantly higher response time was observed in the elderly group while answering the comprehension questions and performing some of the neuropsychological tests. Also a lower performance in working and episodic memory was registered in the elderly group as compared to the younger adults group.

Keywords: Reading comprehension; narratives; aging; schooling.

\section{Introdução}

A crescente demanda por estudos e publicações a respeito do envelhecimento é impulsionada pelo aumento dessa população em nível mundial, pois, nas últimas décadas, houve um aumento significativo no grupo etário acima dos 60 anos. A Organização Mundial da Saúde (OMS) prevê que até 2050 o número de pessoas com mais de 65 anos cresça $70 \%$ e o número de pessoas com mais de 80 anos cresça $170 \%$. Essa projeção no aumento da população idosa reflete mudanças em vários ramos da sociedade.

O envelhecimento normal envolve um declínio gradual de algumas funções cognitivas, dependentes de processos neurológicos que se alteram com a idade. Entre as funções cognitivas - atenção, linguagem, função executiva, memória, habilidades visuoespaciais, entre outras - a memória é uma das mais afetadas. Conforme Canineu et al. (2006), as deficiências de memória, principalmente as que refletem dificuldades para recordar nomes, números de telefones e 
objetos guardados, são as mais relatadas atualmente. Conforme Parente et al. (2006), o envelhecimento, assim como as outras etapas da vida, é um processo de transformação do organismo que se reflete nas suas estruturas físicas, nas manifestações da cognição, bem como na percepção dessas modificações. Com o avanço da idade percebe-se certo declínio em algumas capacidades cognitivas. Conforme Argimon e colegas (2006) a presença de déficits cognitivos pode acarretar dificuldades em atividades do dia a dia dos idosos, além de alterar a autoestima e a qualidade de vida. Bee (1997) comenta que é a partir dos 65 anos que as mudanças cognitivas começam a ser melhor percebidas, mas é em torno dos 75 anos que se verifica a aceleração do declínio físico e cognitivo. O envelhecimento tende a acarretar mudanças associadas a aspectos físicos, como a acuidade auditiva, a força muscular, e outras, cognitivas. Por exemplo, muitos idosos chegam aos 80 anos em condições satisfatórias de saúde, mas é perceptível que grande parte das pessoas apresenta dificuldades relacionadas à memória. Em geral, as recordações do passado mais longínquo permanecem ativas; entretanto, a memória pode falhar quando se tratar de recordações ligadas a acontecimentos mais recentes.

Além do desempenho das capacidades cognitivas, o nível de escolaridade do idoso parece interagir com sua capacidade de compreensão leitora, conforme Parente et al. (2006). Cabe ressaltar que a importância do conhecimento sobre o papel da escolaridade no funcionamento cerebral está relacionada a um considerável número de pesquisas que trazem evidências comportamentais e de neuroimagem da influência da escolaridade sobre o desempenho em tarefas neuropsicológicas, na organização cerebral e como um fator protetor para patologias neurológicas (PARENTE et al., 2009). Além da escolaridade, a literatura tem apontado que diferenças individu- 
ais, como a capacidade de memória (em seus diferentes componentes), influenciam no processamento de um texto, facilitando ou não o processo.

Ainda há a ressaltar que habilidades como memória, linguagem e processamento de textos estão sendo alvo de inúmeras pesquisas durante o envelhecimento. Entre os objetivos dessas pesquisas, estão os de identificar transformações e detectar os fatores etiológicos de possíveis modificações na linguagem decorrentes do envelhecimento. Entretanto, conforme Fonseca e colegas (2007), a relação entre o processo de envelhecimento e as habilidades funcionais da linguagem ou comunicativas vem sendo investigada apenas em nível internacional, com exceção de alguns estudos em nível nacional (BRANDÃO, 2001; PARENTE et al., 1999) sobre o processamento discursivo em idosos. Estudos que visem estabelecer uma relação entre as habilidades de compreensão leitora e as capacidades cognitivas, como a memória, são mais escassos ainda, nacional e internacionalmente.

Neste artigo, pretendeu-se retratar como se dá a compreensão do texto narrativo por leitores idosos e leitores jovens de alta escolaridade. Acreditamos que essa questão é extremamente relevante porque permitiu caracterizar, dentro da região do Vale do Rio Pardo (RS), a capacidade de compreensão leitora de uma amostra da população idosa, buscando identificar uma possível variabilidade nos níveis de compreensão de acordo com a capacidade de memória. Relacionaram-se, assim, os dados advindos das tarefas de compreensão leitora com os de testes neuropsicológicos mensurando o processamento da memória de trabalho e episódica dos dois grupos da pesquisa. Os dados colhidos permitiram delinear um perfil leitor destes grupos e, além disso, contribuíram para uma reflexão sobre o papel da memória no processamento do texto por idosos. Na primeira parte do 
texto, serão apresentadas algumas considerações acerca do envelhecimento de modo geral. Logo após iremos relacionar a questão do envelhecimento e o processamento da linguagem.

\section{Envelhecimento cognitivo}

O processo de envelhecimento ocorre como consequência do acúmulo dos efeitos ambientais que interagem com o organismo e se relaciona com os processos geneticamente programados das mudanças produzidas pelo efeito do tempo. É importante ressaltar, porém, que essas mudanças não ocorrem para todas as pessoas do mesmo modo e no mesmo momento; isto é, não existe uniformidade em relação a elas. Além disso, aspectos culturais, escolaridade, hábitos diários, convivência social, entre outros, influenciam o modo como o indivíduo chega nessa fase da vida. Quando se trata de caracterizar uma pessoa idosa, é preciso levar em conta essas variações individuais, que são determinantes do modo de envelhecer. Por exemplo: há idosos com 65 anos sofrendo de doenças crônicas, com pouca autonomia, enquanto há outros com 80 anos que participam ativamente da vida social e têm uma boa imagem de si próprios.

As mudanças funcionais que ocorrem com o avanço da idade são atribuídas a vários fatores, como por exemplo, "defeitos genéticos, surgimento de doenças e fatores ambientais" (HOFMANN, 2002). Ainda segundo a mesma autora, embora seja uma fase previsível da vida, o processo de envelhecimento não é geneticamente programado, como se acreditava antigamente. Não existem genes que determinam como e quando envelhecer. Há sim, genes variantes cuja expressão favorece a longevidade ou reduz a duração da vida. Nesse sentido, se considerarmos que fatores ambientais e estilo de vida influenciam no envelhecimento, é possível pensar, então, que 
não há um tempo, um período pré-determinado e fixado para o declínio de habilidades. Logo, o modo como o indivíduo se comporta durante a vida adulta irá refletir diretamente no desempenho de suas habilidades quando envelhecer.

Inevitavelmente, segundo Izquierdo (2004), com o avanço da idade, grande parte dos indivíduos vai perdendo a "força" e a eficiência em todas as funções nervosas, ou seja, vai ficando cada vez mais surdo, perde em parte a visão, diminui seus reflexos, seu apetite sexual, sua capacidade de locomoção (primeiro de correr, depois de caminhar), sua capacidade de se lembrar das coisas, de entender, de formar novas memórias e de pensar. Mas por outro lado, Moraes e colegas (2010) ressaltam que a definição de quais e como as funções psíquicas/cognitivas se modificam no decorrer dos anos possibilitou a construção de uma importante consideração: a de que o idoso não seja tratado como um ser limitado cognitivamente, ao mesmo tempo não deixando de reconhecer que o envelhecimento requer a adaptação de estímulos ambientais para que as funções cognitivas do idoso persistam com funcionalidade comparável à de adultos jovens. Em resumo, entende-se que nessa fase da vida é preciso ir além dos aspectos relacionados à saúde, ao sistema biológico, e compreender que nesse período é preciso desenvolver competências que permitam ao idoso realizar o mínimo de suas tarefas básicas diárias de forma autônoma.

Nesse sentido, é da maior importância esclarecer o modo de funcionamento de algumas funções cognitivas como memória e linguagem, no período de vida considerado, estabelecendo relações mais claras entre essas funções e o processo de envelhecimento. Tal conhecimento permitiria entender um pouco melhor como e por que se processa o declínio de tais funções e quais os fatores mais 
importantes para a sua manutenção e, também, para a sua prevenção e retardamento.

\subsection{A memória no envelhecimento}

Como já mencionado, o envelhecimento tende a acarretar mudanças associadas a aspectos físicos, como acuidade auditiva, força muscular, e outras, cognitivas. Por exemplo, muitos idosos chegam aos 80 anos em condições satisfatórias de saúde, mas é perceptível que grande parte das pessoas apresenta dificuldades relacionadas à memória.

A memória é uma das mais importantes funções cognitivas do ser humano. Ela representa a base para o desenvolvimento da linguagem, do reconhecimento das pessoas e dos objetos com que temos contato diariamente, entre outras capacidades essenciais para a convivência social e organização pessoal. Baddeley (1986) afirma que a memória é uma característica própria da espécie humana, sem a qual seríamos vegetais, intelectualmente mortos.

O conjunto de memórias de cada um determina quem ele é e a sua forma de ser. "O acervo de nossas memórias faz com que cada um de nós seja o que é; faz com que sejamos, cada um, um indivíduo, um ser para o qual não existe outro idêntico" (IZQUIERDO, 2002, p.10). Nesse sentido, somos o que somos porque temos memória.

A formação de uma memória pode ser divida em estágios: 1) a codificação subdividida em aquisição e consolidação; 2) o armazenamento (conservação) e 3) a evocação (ou acesso) das informações. A codificação refere-se ao processamento da nova informação a ser armazenada e divide-se em duas fases: "a aquisição, que registra as informações em arquivos sensoriais e estágios de análise sensorial, enquanto a consolidação cria uma forte representação da informação através do tempo" (GAZZANIGA, 2006, p. 320). Conforme o 
mesmo autor, o armazenamento é o resultado da aquisição e consolidação e cria também um registro permanente. Por último, a evocação utiliza a informação armazenada para criar uma representação consciente ou para executar um comportamento aprendido como um ato motor (acessado inconscientemente). Para complementar, citamos Izquierdo (2004), que denomina a evocação como sendo um tipo de recordação ou lembrança.

Atualmente, diversos pesquisadores investigam como se formam as memórias, a qualidade e a tipologia das memórias armazenadas no cérebro, a capacidade de armazenamento de informações, a localização e a duração das memórias, entre outros aspectos.

Entre as diversas classificações existentes para a memória, a mais usual em pesquisas relacionadas à Neuropsicologia refere-se ao modelo tradicional, proposto por Sternberg (2000), no qual a memória é classificada a partir de três modelos: memória sensorial, memória de curta duração e memória de longa duração.

A memória sensorial pode ser considerada o repositório inicial das inúmeras informações que recebemos por meio dos sentidos. Tais informações, depois de decodificadas, serão transferidas para as memórias de curto e longo prazo ou apagadas. Conforme os estudos realizados por Sternberg (2000), dentro da memória sensorial há uma memória chamada icônica.

O armazenamento icônico é um registro sensorial visual separado, assim chamado porque alguns acreditam que a informação é armazenada na forma de ícones (imagens visuais que representam alguma coisa; os ícones geralmente assemelham-se ao que quer que esteja representado) (STERNBERG, 2000, p. 210). 
Uma característica importante de se ressaltar é que a memória icônica pode ser apagada em instantes, ou seja, a informação permanece durante períodos de tempo muito curtos. Normalmente, tal informação poderá ser transferida para outro tipo de memória ou apagada, se outra informação lhe for sobreposta antes que haja tempo suficiente para a transferência dessa informação para outro repositório de memória, explica Sternberg (2000).

A memória de curto prazo mantém as informações ativas, disponíveis para acesso por alguns segundos, ou até minutos, isto quer dizer que temos acesso a esse tipo de memória, diferentemente da memória sensorial. Há inúmeras pesquisas que buscam verificar a quantidade de itens que a memória de curto prazo consegue armazenar. O pesquisador Miller (1956), considerado um dos pioneiros nesse tipo de pesquisa, observou que a memória de curto prazo consegue armazenar aproximadamente sete itens. $\mathrm{O}$ autor explica que um item pode ser algo simples, como um dígito, ou algo mais complexo, como uma palavra. Por exemplo, se agruparmos uma série de 20 letras ou algarismos em sete itens significativos, podemos nos recordar com mais facilidade, ao passo que teríamos mais dificuldades de recordar 20 itens sem relação alguma.

E, por fim, a memória de longo prazo armazena informações que permanecem conosco durante longos períodos de tempo - semanas, meses, anos, décadas. Conforme Sternberg (2000), todos nós confiamos intensamente na nossa memória de longo prazo, porque é nela que estão arquivadas as informações básicas para o dia a dia, como o nome das coisas e pessoas, o local onde guardamos as coisas. Em relação à quantidade de informações que podem ser armazenadas na memória de longo prazo, o mesmo autor conclui: "não sabemos, nem sabemos como descobrir" (STERNBERG, 2000, p. 213). 


\subsubsection{Um tipo especial ou uma "perspectiva alternativa"1}

Estudos mais antigos propunham que a informação se transferiria diretamente da memória de longo prazo para a de curto prazo e depois retornaria. Com o avanço nos estudos neuropsicológicos, houve a inserção do modelo de memória de trabalho, que representa "aquela parte de memória de longo prazo que abrange todo o conhecimento de fatos e de procedimentos, que tenha sido recentemente ativado na memória, inclusive a breve e transitória memória de curto prazo e seus conteúdos" (STERNBERG, 2000, p. 215). De acordo com essa perspectiva, a memória de trabalho comporta apenas a parte ativada mais recentemente pela memória de longo prazo e transfere esses dados ativados para dentro e para fora em um breve e temporário armazenamento de memória.

Dessa forma, se a memória de trabalho manipula e gera imagens e sons, podemos afirmar que ela está diretamente ligada a vários níveis de informação. Baddeley (1986) sugeriu um modelo integrativo de memória, que sintetiza o modelo de memória de trabalho com a estrutura de Níveis de Tratamento da informação (NDT). Na opinião do autor, a memória de trabalho diz respeito a um sistema de memória responsável pela execução de tarefas mentais, como a resolução de um problema matemático, por exemplo, ou qualquer outra tarefa cognitiva.

Os pesquisadores Baddeley, Anderson e Eysenck (2011) observam que o sistema de memória de trabalho tem quatro componentes: a. um Executivo Central (Central Executive) isento de modalidade e semelhante à nossa capacidade de atenção;

b. uma Alça Fonológica (Phonological Loop) que retém a informação de uma forma fonológica (baseada na fala); 
c. um Esboço Visuoespacial (Visuo-spatial Sketchpad) especializado em codificação espacial e visual; e

d. um Buffer Episódico (Episodic Buffer), que é um sistema de armazenamento temporário que pode reter e integrar as informações da alça fonológica e da memória de curto prazo, integrando-as a informações da memória de longo prazo, necessárias para um determinado tipo de processamento. Ele, assim como a Alça Fonológica e o Esboço Visuoespacial, são controlados pelo Executivo Central.

O executivo central é responsável por coordenar as informações recebidas de diferentes fontes, além de ser o depositário e o controlador dos recursos de processamento. Parente et al. (2006) mencionam que esse sistema possui recursos atencionais (compreensão, raciocínio e aprendizagem) e é o componente mais importante desse tipo de memória. Dessa forma, a ativação dos sistemas permite coordenar as diferentes informações recebidas. "O executivo central consegue, pela atividade consciente, recuperar a informação armazenada, fazer uma reflexão acerca da informação, manipular e modificar a ação em curso" (PARENTE et al., 2006, p. 70). Como já mencionado, a memória de trabalho é auxiliada por outros três sistemas de apoio responsáveis pelo arquivamento temporário e a manipulação de informações. Em relação ao sistema de natureza fonológica e ao de natureza visuoespacial, Lasca (2003) faz a seguinte colocação:

Esses sistemas modulares interdependentes incluídos na operação da memória de trabalho seriam responsáveis pela retenção da informação em códigos particulares. A alça visuo-espacial reteria informação sob um código visuo-espacial. A alça fonológica (assim denominada por Baddeley em 1990, inicialmente 
conhecida como alça articulatória), contribuiria para a retenção e manipulação da informação verbal (LASCA, 2003, p. 11).

A alça fonológica, denominada também como circuito fonológico, é especializada em armazenar informações verbais e, por sua vez, está ligada à linguagem. Conforme Parente et al. (2006), essa alça é composta por um armazenamento fonológico e por um processo de recapitulação articulatória. A ação se dá quando "o armazenamento fonológico recebe a informação verbal apresentada auditivamente, transforma-a em códigos fonológicos e a transfere para sua decodificação articulatória" (PARENTE et al., 2006, p. 70).

A alça fonológica é responsável pelo processamento e armazenamento temporário de informações verbais escritas ou faladas, através de um processo de ensaio articulatório. Um exemplo dessa função seria uma situação em que temos que manter na memória um novo número de telefone enquanto estamos fazendo uma chamada telefônica. Alguns segundos após a ligação, não conseguimos mais recordar essa sequência de números. De fato, informações mantidas na alça fonológica podem ser esquecidas ou armazenadas na memória de longo prazo. A alça fonológica está intimamente associada a processos linguísticos. Pessoas que apresentam facilidade para falar, compreender texto, bem como aprender uma nova língua, provavelmente têm uma alça fonológica bem desenvolvida (LANDEIRA-FERNANDEZ, CHENIAUX, 2010).

A alça visuoespacial, também chamada de esboço visuoespacial, armazena e manipula imagens mentais e está relacionada, de forma direta, com a memória declarativa visual.

O funcionamento do esboço visuoespacial é muito parecido com o da alça fonológica, exceto pelo fato de que processa e ar- 
mazena informações visuais (por um curto período de tempo), sendo também capaz de manipular mentalmente essas imagens. [...] Pessoas que apresentam facilidade para visualizar espaços, como, por exemplo, arquitetos e engenheiros, têm presumivelmente apresentam uma alça visuoespacial bem desenvolvida (LANDEIRA-FERNANDEZ, CHENIAUX, 2010).

Buscando explicar como as informações visual e fonológica, vindas de diferentes fontes, se combinam, Baddeley propôs a existência de um terceiro subsistema: a alça episódica, como já mencionado, ligada diretamente à memória episódica. A memória episódica se refere a eventos com um contexto espacial e temporal específico. Assim sendo, a alça episódica se refere ao "sistema de armazenamento temporário de episódios integrados em tempo e espaço, de capacidade limitada, mas que é capaz de integrar informações de diferentes modalidades" (PARENTE et al., 2006, p. 71). A alça episódica é de suma importância para explicar as memorizações temporárias em tarefas que dispõem de grande quantidade de informações significativas, como por exemplo, o reconto de uma história. A alça episódica está conectada com a memória declarativa episódica.

O retentor episódico, o componente mais recentemente descrito da memória de trabalho, é o responsável pela integração das informações mantidas na memória de trabalho em um episódio único que faça sentido para o indivíduo, funcionando como um elemento de comunicação entre o executivo central e a memória de longo prazo, seja através dos processos de consolidação (passagem de uma informação da memória de trabalho para a memória de longo prazo) ou de evocação (passagem de uma informação da memória de longo prazo para a memória de trabalho) (LANDEIRA-FERNANDEZ, CHENIAUX, 2010). 
O executivo central distribui a atenção para que diferentes atividades possam ser realizadas, como subir uma escada, abrir a porta do quarto, pegar um papel e uma caneta, enquanto existe uma memorização contínua de um número telefônico que deverá ser escrito.

Embora possamos armazenar tantas experiências quanto possível, é importante ressaltar que, tão importante quanto o armazenamento das informações é o seu esquecimento. De acordo com Izquierdo (2004), o esquecimento é fisiológico e desempenha um papel adaptativo. Seria praticamente impossível armazenar tudo o que vivenciamos com uma riqueza de detalhes, porque levaríamos muito tempo recordando cada detalhe vivenciado. Conforme Barros (2004) há dois tipos de esquecimento: a extinção e o esquecimento patológico. As memórias extintas permanecem latentes e não são evocadas, "a menos que aconteça uma apresentação de uma forma muito precisa do estímulo (da situação) utilizado para adquiri-las e/ou com uma intensidade muito aumentada, uma dica muito apropriada" (BARROS, 2004, p. 5). Dessa forma, as memórias extintas podem ser evocadas. Por outro lado, quando o esquecimento é patológico, não há como evocar a memória desejada. Nesses casos, a doença que afeta a memória, provocando o esquecimento patológico das informações, é uma doença do tipo degenerativo, como a Doença de Alzheimer. No início da doença, o indivíduo esquece fatos mais recentes, ligados à memória de trabalho. À medida que a doença evolui, a memória de longa duração é afetada, provocando, assim, o não reconhecimento dos parentes, das pessoas mais próximas, perda das habilidades e, por fim, da sua própria identidade (BARROS, 2004). No entanto, o exercício repetitivo da memória em suas diversas formas pode auxiliar na prevenção ou retardar o aparecimento desse tipo de doença.

Estudos que vinculam as mudanças nas regiões cerebrais com o declínio cognitivo no idoso propõem que a diminuição da porção 
dorso-lateral da região pré-frontal dificulta a realização de tarefas dependentes das funções executivas e memória de trabalho (MORAES et al., 2010). As Funções Executivas (FE), ligadas aos componentes cognitivos, estão relacionadas, de maneira geral, à capacidade do indivíduo de engajar-se em comportamento orientado a objetivos, ou seja, à realização de ações voluntárias, independentes, autônomas, auto-organizadas e orientadas para metas específicas (GAZZANIGA et al., 2006). Os mesmos autores explicam que as FE estão entre os aspectos mais complexos da cognição e envolvem seleção de informações, integração de informações atuais com informações previamente memorizadas, planejamento, monitoramento e flexibilidade cognitiva.

A preservação do funcionamento executivo reflete a capacidade de adaptação, tanto na realização de tarefas do cotidiano com as mais complexas. As FE se relacionam particularmente na adequação do desempenho para iniciar, persistir e completar tarefas, assim como na identificação de imprevisto e valorização de qual sua importância, e na elaboração de respostas alternativas diante de novas situações. Há evidências que as FE decaem no processo de envelhecimento.

Em relação à atenção, Moraes (2010) complementa que o processo de atenção representa um grupo complexo de comportamentos, em que o indivíduo pode selecionar informações e ignorar outras; sustentar a concentração em uma informação por um período de tempo; dividir a atenção entre dois ou mais aspectos ao mesmo tempo; e mudar o foco da atenção quando for necessário. No processo de envelhecimento, a capacidade do idoso de dividir atenção entre vários estímulos para apreender uma situação é extremamente prejudicada.

A partir do que foi exposto até agora, é possível identificar que há um declínio representativo de algumas funções cognitivas como memória de trabalho e episódica, atenção e funções executivas no processo de envelhecimento. 


\section{Envelhecimento e processamento da linguagem}

A partir do século XX, período em que as Ciências Cognitivas passaram a ter maior projeção, houve um aumento no interesse em pesquisas que analisassem o funcionamento da mente e, junto a isso, a relação entre a linguagem e o cérebro. Tanto que a linguagem passou a ser vista como uma verdadeira janela para as investigações cérebro/mente (PINKER, 1999).

A linguagem é uma habilidade exclusivamente humana e se constitui como um dos aspectos fundamentais na vida do homem. Conforme Rabadán (1998), a capacidade de comunicação é um instrumento de interação social por excelência e se desenvolve no decorrer da vida. Através da linguagem as pessoas transmitem conhecimentos referentes à história geral e individual, resolvem problemas, expressam sentimentos, ideias, pensamentos.

Como com relação à memória, existem estudos que mostram que o envelhecimento traz declínio a algumas habilidades linguísticas. Cancela (2007) comenta, porém, que a capacidade de se comunicar eficazmente através da linguagem mantém-se estável durante toda a vida adulta. Contudo, as pessoas idosas têm maior dificuldade de compreender mensagens longas, ou complexas, e em recuperar e produzir, rapidamente, nomes ou termos específicos. O discurso também tende a ser mais repetitivo. Assim, tem-se de considerar que as habilidades linguísticas incluem falar, ouvir, ler e escrever, daí a relevância de conhecer em mais detalhes a interação leitura - envelhecimento, por exemplo, a partir da compreensão, pois ler sem entender não é, propriamente, ler. 


\subsection{A compreensão da leitura no envelhecimento}

Evidências trazidas pela literatura advinda tanto de estudos comportamentais quanto dos com neuroimagem estrutural ou funcional têm enfatizado que o processamento do discurso no envelhecimento (tanto quanto a linguagem em geral, independentemente da idade) não pode ser analisado de forma dissociada de outros componentes da cognição humana, como a memória, a atenção, a inibição, entre outros (SKA et al., 2009). Como exemplo, podem-se citar os três aspectos que têm sido prioritariamente estudados em termos de memória, linguagem e envelhecimento: dissociações entre memória declarativa e procedimental (ou procedural), o papel de áreas pré-frontais do hemisfério direito e do esquerdo no fenômeno de familiaridade, bem como o papel do córtex pré-frontal na função da memória de trabalho (KRAMER et al., 2006). Sempre que um desses componentes cognitivos se altera como causa do avanço da idade, uma alteração no funcionamento da comunicação é esperada. Essas alterações têm sua origem em bases neurofisiológicas (para uma revisão mais completa consultar Ska et al., 2009). Apesar do crescimento da literatura sobre as diferenças e semelhanças no processamento de texto ao longo da vida, ainda faltam estudos mais conclusivos sobre o tema.

Em face da importante escassez de estudos sobre processamento do discurso no envelhecimento e do conhecimento ainda restrito quanto à relação dos componentes linguísticos envolvidos na leitura de textos e em tarefas que mensuram outros componentes cognitivos, o presente estudo tem por objetivo comparar o processamento do texto narrativo por leitores adultos jovens versus leitores adultos idosos. Além disso, visa investigar se há relação entre esta habilidade leitora e sistemas de memória (episódica e de trabalho). 
A pesquisa apresentada a seguir foi aprovada pelo Comitê de Ética em Pesquisa da Universidade de Santa Cruz do Sul (UNISC).

\section{Método}

\subsection{Participantes}

A amostra total deste estudo contou com a participação de 23 adultos. A amostra final foi composta por 20 indivíduos por exclusão de 3 participantes que não completaram a avaliação ou que apresentavam sinais sugestivos de depressão. Foi dividida em dois grupos conforme a idade: (1) grupo de adultos jovens, $n=10$, com idades entre 20 e 35 anos, e (2) grupo de adultos idosos, $n=10$, com idades entre 60 e 75 anos. Foram incluídos na amostra apenas os participantes que reportaram, por auto-relato, ausência de histórico de doenças psiquiátricas ou neurológicas, de consumo de substâncias psicoativas, de alterações sensoriais e apresentaram escores não sugestivos de depressão e/ou declínio cognitivo.

A Tabela 1 resume os dados sociodemográficos dos grupos. Todos os participantes tinham alto nível de escolaridade, isto é, possuíam nove anos ou mais de ensino formal. Os grupos contrastantes não apresentaram diferenças estatísticas em nenhuma das variáveis sociodemográficas, com exceção da variável idade, e clínicas.

\section{Tabela 1 - Dados sociodemográficos e clínicos dos participantes}

\begin{tabular}{lllllll}
\hline \multirow{2}{*}{ Variáveis } & \multicolumn{7}{c}{ Adultos jovens } & \multicolumn{2}{c}{ Adultos idosos } & \multirow{2}{*}{$p$} \\
\cline { 2 - 5 } & $\mathrm{M}$ & $\mathrm{DP}$ & $\mathrm{M}$ & $\mathrm{DP}$ & & \\
\hline Idade & 25,00 & 4,99 & 64,80 & 3,85 & $-19,97$ & $<0,001$ \\
Anos de estudo & 16,10 & 3,14 & 15,80 & 4,39 & 0,18 & 0,863
\end{tabular}


Lilian Cristine Scherer et al., O processamento da narrativa no...

$\begin{array}{lllllll}\begin{array}{l}\text { Frequência de hábitos } \\ \text { de leitura e de escrita }\end{array} & 16,83 & 4,79 & 14,44 & 4,00 & 1,05 & 0,314 \\ \text { GDS-15 } & 1,40 & 1,43 & 1,70 & 1,57 & -0,45 & 0,660 \\ \text { MEEM } & 27,75 & 2,25 & 27,00 & 1,94 & 0,74 & 0,472 \\ \text { Sexo (Masculino/Fe- } & 1 / 9 & & 4 / 6 & & & 0,303 \\ \text { minino) } & & & & & & \end{array}$

Nota. GDS-15 = Escala de Depressão Geriátrica de 15 pontos; MEEM = Mini Exame do Estado Mental; gl = 18 .

\subsection{Procedimentos e Instrumentos}

Os participantes foram avaliados individualmente em duas sessões: uma sessão de aproximadamente 90 minutos, durante a qual, após lerem e assinarem o Termo de Consentimento Livre e Esclarecido para a participação na pesquisa, respondiam a um questionário geral de aspectos de saúde e culturais, outro sobre hábitos de leitura e escrita e desenvolviam as tarefas neuropsicológicas descritas abaixo; outra sessão, de duração aproximada de uma hora, na qual liam dois textos impressos (um narrativo e outro, argumentativo) e respondiam a questões de compreensão leitora correspondentes a cada texto, apresentadas na tela de um computador. Neste artigo, abordam-se os dados relacionados à leitura de apenas um dos textos, o narrativo

Na primeira sessão, os questionários possibilitavam a caracterização da amostra, verificando critérios de inclusão e investigando a frequência de hábitos de leitura e de escrita, mensurada por meio de uma escala Likert, com variação entre 0 a 4 pontos, que classificava a frequência da leitura de livros, revistas, jornais, dentre outros, e a frequência de escrita de textos, recados, dentre outros. Os participantes ainda responderam ao MEEM e GDS-15 com a finalidade de avaliar 
a presença de declínio cognitivo e sinais sugestivos de depressão, respectivamente. A avaliação neuropsicológica foi composta por testes ou tarefas, aplicados na seguinte ordem:

- $\quad$ Trail Making Test (TMT) (AITB, 1942, STRAUSS et al., 2006): avalia atenção dividida e alternada, controle inibitório, flexibilidade cognitiva e velocidade psicomotora;

- Teste de aprendizagem auditivo-verbal de Rey (MALLOY-DINIZ et al., 2007; REY, 1964): mensura memória episódica verbal de evocação imediata, tardia e reconhecimento, além da capacidade de aprendizagem verbal;

- Evocação lexical (fluência verbal) livre, ortográfica e semântica - subtestes da Bateria Montreal de Avaliação da Comunicação Bateria MAC (FONSECA et al., 2007a , 2008): investiga memória léxico-semântica, busca lexical, velocidade de processamento, planejamento, iniciação e inibição verbais;

- Span auditivo de palavras em sentenças - subteste do Instrumento de Avaliação Neuropsicológica Breve NEUPSILIN (FONSECA, SALLES \& PARENTE, 2009): avalia os componentes executivo central e retentor episódico da memória de trabalho, predominantemente.

$\mathrm{Na}$ segunda sessão, os participantes leram individualmente o texto narrativo "Catapultados" (VERÍSSIMO, 2008), impresso, e, em seguida, após uma tarefa de familiarização, respondiam ao instrumento para avaliação da compreensão leitora referente ao texto. As questões foram apresentadas pelo sofware EPrime ${ }^{2}$ na tela de um computador. Eram 11 questões de múltipla escolha, que procuraram 
abranger uma variada gama de aspectos possíveis de serem explorados na verificação da compreensão leitora, desde níveis mais superficiais, como a lembrança de detalhes do texto ou o significado de palavras, até os mais abrangentes, determinados pelo conhecimento de mundo do leitor, demandando vários graus de inferenciação.

\subsection{Análise dos dados}

A comparação de desempenho entre os grupos etários foi realizada pelo pacote estatístico SPSS 17, por meio do Teste $t$ de Student, considerando-se nível de significância $p \leq 0,05$. Além disso, promoveu-se uma análise de correlação de Pearson.

\subsection{Apresentação e discussão dos resultados}

Os dados obtidos da comparação entre os dois grupos etários são resumidos na Tabela 2. Os instrumentos foram agrupados de acordo com as funções cognitivas avaliadas.

Tabela 2 - Dados comparativos entre grupos etários quanto ao desempenho neuropsicológico

\begin{tabular}{llllll}
\hline \multirow{2}{*}{ Processamentos } & \multicolumn{4}{l}{ Adultos jovens } & Adultos idosos \\
\cline { 2 - 5 } & $\mathrm{M}$ & $\mathrm{DP}$ & $\mathrm{M}$ & $\mathrm{DP}$ & \\
\hline
\end{tabular}

MEV \& RAVLT A4

AV

- $\mathrm{n}^{\circ}$ palavra

$10,80 \quad 2,15 \quad 8,60$

1,71

$2,53 \quad 0,021$

evocadas

RAVLT A5

$-\mathrm{n}^{\circ}$ palavras

$11,90 \quad 1,73 \quad 9,40$

1,96

$3,03 \quad 0,007$

evocadas

RAVLT A5 intrusões

$0,00 \quad 0,00 \quad 0,40$

0,52

$2,45 \quad 0,037$ 


\begin{tabular}{|c|c|c|c|c|c|c|c|}
\hline & $\begin{array}{l}\text { RAVLT A6 } \\
-\mathrm{n}^{\circ} \text { palavras } \\
\text { evocadas }\end{array}$ & 10,00 & 2,98 & 7,10 & 2,69 & 2,29 & 0,035 \\
\hline & $\begin{array}{l}\text { RAVLT A7 - } \\
\text { intrusões }\end{array}$ & 0,20 & 0,63 & 1,56 & 1,33 & 2,78 & 0,018 \\
\hline & $\begin{array}{l}\text { RAVLT - re- } \\
\text { conhecimento }\end{array}$ & 12,70 & 2,31 & 9,00 & 1,41 & 3,75 & 0,002 \\
\hline & $\begin{array}{l}\text { RAVLT - total } \\
\text { de palavras } \\
\text { evocadas A1- } \\
\text { A5 }\end{array}$ & 47,90 & 8,69 & 39,30 & 6,90 & 2,45 & 0,025 \\
\hline \multirow{5}{*}{$\begin{array}{l}\text { AC \& } \\
\text { VP }\end{array}$} & TMT - & & & & & & \\
\hline & Tempo(s) & 28,04 & 12,53 & 50,45 & 12,47 & 4,01 & 0,001 \\
\hline & Parte A & & & & & & \\
\hline & $\begin{array}{l}\text { TMT - } \\
\text { Tempo(s) } \\
\text { Parte B }\end{array}$ & 75,64 & 39,32 & 116,44 & 14,68 & 2,20 & 0,048 \\
\hline & ELS - Bloco 1 & 11,63 & 2,07 & 9,22 & 2,39 & 0,93 & 0,043 \\
\hline \multirow{2}{*}{ MT } & $\begin{array}{l}\text { NEUPSILIN - } \\
\text { SAPS }\end{array}$ & 21,80 & 4,69 & 16,60 & 5,50 & 2,28 & 0,035 \\
\hline & $\begin{array}{l}\text { NEUPSILIN - } \\
\text { SAPS (bloco) }\end{array}$ & 3,80 & 0,92 & 2,70 & 1,16 & 2,35 & 0,030 \\
\hline
\end{tabular}

Nota MEV = Memória verbal episódica; $\mathrm{AV}=$ Aprendizagem verbal; $\mathrm{AC}=$ Atenção concentrada; VP = Velocidade de processamento; $\mathrm{MT}=$ Memória de trabalho; RAVLT = Rey Auditory Verbal Learning Test; SAPS = Span Auditivo de Palavras em Sentenças.

De acordo com a comparação realizada, o grupo de adultos jovens obteve melhores resultados nas tarefas de memória verbal episódico-semântica de evocação imediata, tardia e de reconhecimento, cometendo menos intrusões. Resultado semelhante é encontrado ao se considerar velocidade de processamento e memória de trabalho.

A Tabela 3 apresenta os resultados da tarefa de compreensão leitora. 
152 Lilian Cristine Scherer et al., O processamento da narrativa no...

Tabela 3 - Comparação entre grupos etários quanto à acurácia e ao Tempo de Resposta (TR) nas variáveis de compreensão leitora

\begin{tabular}{|c|c|c|c|c|c|c|c|}
\hline \multirow[t]{2}{*}{ Variáveis } & & \multicolumn{2}{|l|}{$\begin{array}{l}\text { Adultos } \\
\text { jovens }\end{array}$} & \multicolumn{2}{|l|}{$\begin{array}{l}\text { Adultos } \\
\text { idosos }\end{array}$} & \multirow[t]{2}{*}{$t$} & \multirow[t]{2}{*}{$\mathrm{p}$} \\
\hline & & $\mathrm{M}$ & DP & $\mathrm{M}$ & DP & & \\
\hline Inferências & TR & 58653,10 & 16503,12 & 101217,50 & 29795,46 & $-3,95$ & 0,001 \\
\hline $\begin{array}{l}\text { nível global } \\
\text { (questões V } \\
\text { ou F) }\end{array}$ & Acurácia & 7,90 & 1,45 & 8,70 & 1,95 & $-1,04$ & 0,311 \\
\hline \multirow[t]{2}{*}{$\begin{array}{l}\text { Coerência } \\
\text { textual }\end{array}$} & TR & 31298,30 & 19030,76 & 51518,90 & 29424,85 & $-1,83$ & 0,085 \\
\hline & Acurácia & 2,00 & 0,94 & 1,60 & 0,84 & 1,00 & 0,331 \\
\hline \multirow[t]{2}{*}{$\begin{array}{l}\text { Coerência } \\
\text { extratextual }\end{array}$} & TR & 49126,00 & 25998,43 & 43544,60 & 39192,12 & 0,38 & 0,712 \\
\hline & Acurácia & 3,11 & 0,60 & 2,10 & 1,20 & 2,28 & 0,036 \\
\hline \multicolumn{8}{|c|}{ Nível semân- TR } \\
\hline tico & Acurácia & 1,40 & 0,84 & 0,90 & 0,74 & 1,47 & 0,175 \\
\hline \multirow[t]{2}{*}{$\begin{array}{l}\text { Nível } \\
\text { lexical }\end{array}$} & TR & 53329,90 & 20558,42 & 74617,80 & 23546,78 & $-2,15$ & 0,045 \\
\hline & Acurácia & 4,00 & 1,05 & 3,50 & 1,18 & 1,00 & 0,331 \\
\hline \multirow{3}{*}{$\begin{array}{l}\text { Memória } \\
\text { para } \\
\text { detalhes }\end{array}$} & TR & & & & & & \\
\hline & & 30086,90 & 14430,81 & 53636,10 & 17875,12 & $-3,24$ & 0,005 \\
\hline & Acurácia & 1,60 & 0,52 & 2,00 & 0,50 & $-1,71$ & 0,105 \\
\hline
\end{tabular}

Nota. $\mathrm{TR}=$ Tempo de Resposta $; \mathrm{V}=$ Verdadeiro; $\mathrm{F}=$ Falso $\mathrm{MC}=$ metafóricocultural.

A Tabela 3 mostra a comparação entre o tempo de resposta quando esta foi considerada correta, assim como a acurácia nas respostas. Observa-se que o grupo de adultos jovens foi mais veloz nas variáveis que avaliavam inferências de nível global, processamento lexical e memória para detalhes. Contudo, só houve diferença significativa de acurácia na variável coerência extratextual que inclui 
conhecimento metafórico e cultural, tarefa na qual os adultos jovens apresentaram melhor desempenho.

A Tabela 4 apresenta apenas os casos em que houve relação significativa entre a compreensão leitora e os dados dos testes neuropsicológicos.

Tabela 4 - Relação entre o desempenho nas questões de compreensão leitora e o desempenho nos testes neuropsicológicos para amostra geral

\begin{tabular}{|c|c|c|c|c|c|c|c|}
\hline & & ING & $\mathrm{CT}$ & CEt & NS & $\mathrm{NL}$ & $\mathrm{MD}$ \\
\hline \multirow{2}{*}{$\begin{array}{l}\text { RAVLT Total } \\
\text { treino A1-A5 }\end{array}$} & $\mathrm{r}$ & 0,199 & 0,116 & 0,384 & 0,046 & 0,246 & $-0,034$ \\
\hline & $\mathrm{p}$ & 0,400 & 0,626 & 0,105 & 0,849 & 0,297 & 0,889 \\
\hline \multirow{2}{*}{$\begin{array}{l}\text { RAVLT } \\
\text { Interferência }\end{array}$} & $\mathrm{r}$ & $-0,333$ & $-0,022$ & $-0,010$ & 0,111 & $-0,022$ & $-0,063$ \\
\hline & $\mathrm{p}$ & 0,151 & 0,925 & 0,967 & 0,640 & 0,925 & 0,798 \\
\hline \multirow{2}{*}{$\begin{array}{l}\text { RAVLT } \\
\text { Evocação } \\
\text { tardia }\end{array}$} & $\mathrm{r}$ & 0,011 & 0,180 & 0,104 & $-0,170$ & $-0,086$ & $-0,119$ \\
\hline & $\mathrm{p}$ & 0,963 & 0,460 & 0,681 & 0,487 & 0,727 & 0,638 \\
\hline \multirow{2}{*}{$\begin{array}{l}\text { RAVLT } \\
\text { Reconheci- } \\
\text { mento } \\
\end{array}$} & $r$ & $-0,032$ & 0,145 & 0,051 & 0,255 & 0,195 & $-0,203$ \\
\hline & $\mathrm{p}$ & 0,902 & 0,578 & 0,850 & 0,323 & 0,453 & 0,434 \\
\hline \multirow{2}{*}{$\begin{array}{l}\text { WCST } \\
\text { Categorias }\end{array}$} & $\mathrm{r}$ & 0,240 & 0,056 & 0,231 & 0,419 & 0,346 & $-0,686$ \\
\hline & $\mathrm{p}$ & 0,505 & 0,878 & 0,520 & 0,228 & 0,327 & 0,028 \\
\hline \multirow{2}{*}{$\begin{array}{l}\text { WCST Erros } \\
\text { perseverativos }\end{array}$} & $\mathrm{r}$ & 0,393 & 0,162 & 0,360 & 0,270 & 0,301 & 0,534 \\
\hline & $\mathrm{p}$ & 0,296 & 0,678 & 0,341 & 0,483 & 0,432 & 0,139 \\
\hline \multirow{2}{*}{$\begin{array}{l}\text { WCST Erros } \\
\text { não-persever- } \\
\text { ativos }\end{array}$} & $\mathrm{r}$ & $-0,144$ & 0,251 & $-0,190$ & $-0,419$ & $-0,071$ & 0,308 \\
\hline & $\mathrm{p}$ & 0,712 & 0,514 & 0,624 & 0,262 & 0,856 & 0,420 \\
\hline \multirow{2}{*}{$\begin{array}{l}\text { TMT } \\
\text { Tempo(s) } \\
\text { Parte A }\end{array}$} & $\mathrm{r}$ & 0,215 & $-0,148$ & $-0,380$ & $-0,288$ & 0,008 & 0,360 \\
\hline & $\mathrm{p}$ & 0,363 & 0,534 & 0,108 & 0,219 & 0,975 & 0,130 \\
\hline
\end{tabular}


154 Lilian Cristine Scherer et al., O processamento da narrativa no...

\begin{tabular}{|c|c|c|c|c|c|c|c|}
\hline \multirow{2}{*}{$\begin{array}{l}\text { TMT Erros } \\
\text { Parte A }\end{array}$} & $\mathrm{r}$ & $-0,159$ & $-0,225$ & $-0,379$ & $-0,256$ & $-0,289$ & 0,175 \\
\hline & $\mathrm{p}$ & 0,504 & 0,340 & 0,109 & 0,275 & 0,216 & 0,474 \\
\hline \multirow{2}{*}{$\begin{array}{l}\text { TMT } \\
\text { Tempo(s) } \\
\text { Parte B }\end{array}$} & $\mathrm{r}$ & 0,499 & 0,122 & $-0,062$ & $-0,519$ & 0,192 & $-0,163$ \\
\hline & $\mathrm{p}$ & 0,069 & 0,677 & 0,840 & 0,057 & 0,510 & 0,596 \\
\hline \multirow{2}{*}{$\begin{array}{l}\text { TMT Erros } \\
\text { Parte B }\end{array}$} & $\mathrm{r}$ & 0,438 & 0,212 & 0,637 & 0,369 & 0,411 & 0,444 \\
\hline & $\mathrm{p}$ & 0,117 & 0,468 & 0,019 & 0,194 & 0,145 & 0,128 \\
\hline \multirow{2}{*}{$\begin{array}{l}\text { HAYLING } \\
\text { Tempo(s) } \\
\text { Parte A }\end{array}$} & $\mathrm{r}$ & 0,030 & 0,165 & 0,081 & $-0,360$ & $-0,479$ & 0,214 \\
\hline & $\mathrm{p}$ & 0,903 & 0,498 & 0,750 & 0,130 & 0,038 & 0,393 \\
\hline \multirow{2}{*}{$\begin{array}{l}\text { HAYLING Er- } \\
\text { ros Parte A }\end{array}$} & $\mathrm{r}$ & 0,327 & 0,044 & 0,061 & 0,072 & 0,175 & 0,026 \\
\hline & $\mathrm{p}$ & 0,172 & 0,857 & 0,809 & 0,770 & 0,474 & 0,919 \\
\hline \multirow{2}{*}{$\begin{array}{l}\text { HAYLING } \\
\text { Tempo(s) } \\
\text { Parte B }\end{array}$} & $\mathrm{r}$ & 0,186 & $-0,172$ & 0,254 & $-0,138$ & $-0,055$ & 0,321 \\
\hline & $\mathrm{p}$ & 0,432 & 0,469 & 0,295 & 0,560 & 0,819 & 0,180 \\
\hline \multirow{2}{*}{$\begin{array}{l}\text { HAYLING Er- } \\
\text { ros Parte B }\end{array}$} & $\mathrm{r}$ & 0,263 & $-0,102$ & 0,243 & $-0,245$ & $-0,234$ & $-0,135$ \\
\hline & $\mathrm{p}$ & 0,262 & 0,670 & 0,317 & 0,299 & 0,320 & 0,581 \\
\hline \multirow{2}{*}{$\begin{array}{l}\text { NEUPSILIN } \\
\text { SAPS }\end{array}$} & $\mathrm{r}$ & 0,048 & 0,144 & 0,480 & 0,314 & 0,450 & $-0,289$ \\
\hline & $\mathrm{p}$ & 0,842 & 0,545 & 0,038 & 0,177 & 0,046 & 0,230 \\
\hline \multirow{2}{*}{$\begin{array}{l}\text { MAC Evoca- } \\
\text { ção Lexical } \\
\text { Livre }\end{array}$} & $\mathrm{r}$ & 0,492 & 0,303 & 0,385 & 0,096 & 0,215 & 0,342 \\
\hline & $\mathrm{p}$ & 0,032 & 0,208 & 0,115 & 0,697 & 0,377 & 0,165 \\
\hline \multirow{2}{*}{$\begin{array}{l}\text { MAC Evoca- } \\
\text { ção Lexical } \\
\text { Ortográfico }\end{array}$} & $\mathrm{r}$ & 0,252 & 0,018 & 0,468 & 0,165 & 0,352 & 0,166 \\
\hline & $\mathrm{p}$ & 0,365 & 0,949 & 0,092 & 0,556 & 0,198 & 0,571 \\
\hline \multirow{2}{*}{$\begin{array}{l}\text { MAC Evoca- } \\
\text { ção Lexical } \\
\text { Semântico }\end{array}$} & $\mathrm{r}$ & 0,101 & $-0,415$ & 0,044 & $-0,002$ & 0,293 & $-0,240$ \\
\hline & $\mathrm{p}$ & 0,710 & 0,110 & 0,877 & 0,994 & 0,271 & 0,390 \\
\hline
\end{tabular}

Nota: ELL - evocação lexical livre; ELO - evocação lexical com critério ortográfico; ELS - evocação lexical com critério semântico; MAC - Bateria MAC 
Há correlação significativa apenas em flexibilidade cognitiva e memória para detalhes, atenção dividida e processamento metafórico/cultural, velocidade de processamento verbal e nível lexical, memória de trabalho e processamento metafórico/cultural, e memória de trabalho e nível lexical.

\section{Considerações finais}

Os achados desta pesquisa sugerem que o fator idade representando envelhecimento tem certo impacto no processamento do discurso. Em relação à acurácia, houve um desempenho semelhante entre os grupos, na maioria das questões. Entretanto, em apenas um agrupamento de questões (compreensão extratextual) os adultos jovens demonstraram níveis mais altos de acurácia em relação aos idosos. Tal diferença nos níveis de acurácia em tarefas cognitivas pode estar relacionada a uma diminuição de velocidade de processamento e dificuldade de selecionar as informações, dificuldades que podem se manifestar no envelhecimento (SKA et al., 2009; PARENTE et al., 2006). Ainda em relação ao processamento do texto, destaca-se que os idosos obtiveram escores significativamente mais altos nos tempos de resposta.

No que se refere aos resultados advindos dos testes neuropsicológicos, percebeu-se que os idosos apresentaram maior dificuldade para novas aprendizagens, como ficou evidenciado na aplicação do Teste Rey Verbal. Igualmente a partir da aplicação do referido teste, observou-se que a capacidade de memória episódica do adulto idoso era significativamente inferior à dos jovens, o que se percebeu quando aqueles tinham que evocar itens da lista após um intervalo de tempo. Ficou evidente também o declínio das funções executivas, representada pela capacidade de concentração, seletividade de estímulos, capacidade de abstração, planejamento, inibição, entre 
outras. Podemos observar que a grande maioria dessas habilidades cognitivas apresenta um declínio, quando comparada ao processamento cognitivo dos adultos jovens.

Por meio do sub-teste de medida do span auditivo de palavras e frases do NEUPSILIN e da correlação entre tal teste e as questões que avaliaram a compreensão leitora, pode-se verificar que a memória de trabalho parece estar afetada pelo envelhecimento. $\mathrm{O}$ que reforça a maior dificuldade na atenção da qual o idoso tem de lançar mão ao executar tarefas simultâneas, como é o caso do processamento textual.

Algumas limitações podem ser identificadas no presente estudo. Uma delas foi o número reduzido de participantes, o que não permite chegar a dados conclusivos, tampouco plausíveis de serem verdadeiramente representativos dos grupos que representam. A análise estatística também teve de ser adequada ao reduzido número de participantes. Outra limitação é o tempo necessário para a aplicação dos testes. O teste de compreensão leitora da segunda sessão, por exemplo, levava em torno de uma hora para ser concluído e em torno de noventa minutos na primeira sessão eram dedicados à aplicação dos testes neuropsicológicos e dos questionários. Essa extensão de tempo foi um dificultador porque grande parte das pessoas não tinha tal disponibilidade para participar do experimento. $\mathrm{O}$ número de itens testados no teste de compreensão do texto precisou ser compacto a fim de não estender demais o tempo de dedicação dos participantes. Por exemplo, inicialmente, pensou-se em solicitar a produção de um resumo por parte dos indivíduos, bem como um protocolo verbal sobre a compreensão do texto; porém, optou-se por excluir estas tarefas, uma vez que elas tornariam a obtenção dos dados muito mais extensa.

O estudo foi uma proposta inicial de avaliação e relação do processamento do texto e a capacidade de memória e funções executivas no envelhecimento. Poder-se-ia pensar em estender essa pesquisa 
para outros grupos de participantes, como participantes adultos de média idade, a fim de obter-se uma melhor ideia sobre a evolução dos processos de compreensão e sua relação com as habilidades cognitivas, como as aqui testadas. Além disso, grupos comparativos com níveis de escolaridade diferentes poderiam ser analisados, incluindo-se uma amostra comparando diferentes faixas etárias e diferentes níveis de escolaridade na resolução de tarefas que envolvam memória e processamento do texto. Outro estudo poderia utilizar várias tipologias textuais, buscando-se observar se a tipologia textual que influencia os níveis de compreensão dos participantes, segundo sua faixa etária e capacidades cognitivas.

Sabemos que o envelhecimento pode acarretar declínios cognitivos, mas a sua intensidade parece depender de vários fatores determinados pelas diferenças individuais, relacionadas aos hábitos leitura e escrita, à qualidade da interação social, bem como à saúde geral do corpo, como qualidade do sono, da atividade física e da alimentação. Finalmente, é importante salientar que mudanças nem sempre são sinônimo de declínio ou déficit. Fatores como o uso de estratégias compensatórias, a ativação de reservas cognitivas acumuladas ao longo da vida, condições de saúde física e mental, qualidade de vida, entre outros, "co-operam" para a manutenção do bom desempenho cognitivo, incluindo o da linguagem e da comunicação.

\section{Agradecimentos}

- L. C. S. agradece à FAPERGS por apoio financeiro para realização desta pesquisa por meio de concessão de Auxílio Recém-Doutor e à Universidade de Santa Cruz do Sul por auxílio financeiro para a implementação do estudo.

- Os autores agradecem aos graduandos Tiago Silva (bolsista PIBIC) e Júlia Trarbach (Bolsista PROBIC/FAPERGS) pelo auxílio na coleta de dados da pesquisa. 


\section{Notas}

1. Termo proposto por Sternberg (2000) para classificar a memória de trabalho.

2. Disponível em http://www.pstnet.com/products/e-prime

\section{Referências}

Argimon, I. I. L.; Bicca, M.; Timm, L. A.; Vivan, A. Funções executivas e a avaliação de flexibilidade de pensamento em idosos. Revista Brasileira de Ciências do Envelhecimento Humano, Passo Fundo, 35-42 - Jul-Dez.2006.

Azambuja, L. S. Bateria Neuropsicológica para adultos com TDAH. (2010) Disponível em: www.psicologia.com.pt. Acesso em: 28/07/2010.

Baddeley, A.; Anderson, M. C.; Eysenck, M. W. Memória. Porto Alegre: Artmed, 2000

Baddeley, A D. Working memory. Oxford: Oxford Scientific Publications, 1986.

Barros, D. M. A memória. (2004) Disponível em: www.comciencia.br. Acesso em: 15/04/2010.

Bee, H. O ciclo vital. Porto Alegre: Artes Médicas, 1997.

Brandão, L.; Parente, M ${ }^{a}$ A. M. P. Os estudos de linguagem do idoso neste último século. In: Estudos Interdisciplinares sobre o Envelhecimento. Porto Alegre, v. 3, p. 37-53, 2001.

Cancela, D. M. G. O processo de envelhecimento. (2007) Disponível em www.psicologia.com.pt. Acesso em 20/03/2011.

Canineu, P. R.; Stella, F.; Samara, A B. Transtorno cognitivo leve. In: Freitas, E. V.; Py, L.; Néri, A L.; Cançado, F. A X.; Gorzoni, M. L.; Rocha, S. M. (Orgs.) Tratado de Geriatria e gerontologia. Rio de Janeiro: Guanabara, 2006. p. 252-258

Eysenck, Michael William; Keane, Mark T. Manual de psicologia cognitiva. Porto Alegre: Artmed, 2007. 608 p

Folstein, M. F.; Folstein, S. E., \& Mchugh, P. R. Mini-mental state: a practical method for grading the cognitive state of patients for the clinician. Journal of Psychiatric Research, 12, 3: 189-198, 1975. 
Fonseca, R. P.; Ska, B.; Scherer, L. C.; Oliveira, C. R.; Parente, M. A. M. P; Joanette, Y. Mudanças no processamento cognitivo em adultos idosos: déficits ou estratégias adaptativas? In: Estudos Interdisciplinares sobre o Envelhecimento, Porto Alegre, v. 14, n 1, 2009.

Fonseca, R. P.; Parente, M. A. M. P.; Côté, H; Ska, B., \& Joanette, Y. Bateria Montreal de Avaliação da Comunicação - Bateria MAC. São Paulo: PróFono, 2008.

Fonseca, R. P.; Wagner, G. P.; Rinaldi, J.; Parente, Ma . A. M. P. O envelhecimento influencia as habilidades pragmáticas, léxico-semânticas e prosódicas do hemisfério direito. In: Estudos Interdisciplinares sobre o Envelhecimento, Porto Alegre, v.12, p. 53-79, 2007.

Gazzaniga, M. S. Neurociência cognitiva: a biologia da mente. Trad. Angelica Rosat Consiglio [et. al.]. Porto Alegre: Artmed, 2006.

Hoffmann, M. E. Bases biológicas do envelhecimento (2002). Disponível em www.comciencia.br. Acesso em 22/03/2011.

Izquierdo, I. Memória. Porto Alegre: Artmed, 2002.

Izquierdo, I. Questões sobre memória. São Leopoldo: Unisinos, 2004.

Kramer, A.F.; Fabiani, M., \& Colcombe, S.J. Contributions of Cognitive Neuroscience to the Understanding of Behavior and Aging. In J.E.Birren \& K.W. Schaie (Eds.), Handbook of the Psychology of Aging, 6 Ed., Elsevier: New York, 2006.

Landeira-Fernandez, J.; Cheniaux, E. Cinema e loucura: conhecendo os transtornos mentais através dos filmes. Porto Alegre: Artmed, 2010. 287 p.

Lasca, V. B. (2003). Treinamento de memória no envelhecimento normal: um estudo experimental utilizando a técnica de organização. Dissertação de mestrado, Universidade Estadual de Campinas, São Paulo.

Malloy-Diniz, L. F.; Lasmar, V. A. P.; Gazinelli, L. S. R.; Fuentes, D.; Salgado, J. V. The Rey auditory-verbal learning test: applicability for the Brazilian elderly population. Rev Bras Psiquiatr, v. 29, n. 4, 324-329, 2007.

Miller, G. A. The magical number seven, plus or minus two: Some limits on our capacity for processing information. Psychological Review, 63, 2, 343-355, 1956. 
Moraes, E. N.; Moraes, F. L.; Lima, S. P. P. Características biológicas e psicológicas do envelhecimento. Revista Medicina de Minas Gerais, 2010; 20 (1): 67-73.

Parente, Ma . A. M. P. [et al.]. Cognição e envelhecimento. Porto Alegre: Artmed, 2006.

Parente, Ma A. M. P.; Scherer, L. C.; Zimmermann N.; Fonseca, M. P. Evidências do papel da escolaridade na organização cerebral. In: Revista Neuropsicologia Latinoamericana, vol. 1, 2009, 72-80.

Parente, M. A. M. P.; Saboskinsk, A. P.; Ferreira, E.; Nespoulos, J. L. Memória e compreensão da linguagem no envelhecimento. In: Estudos Interdisciplinares do Envelhecimento. Porto Alegre, v. 1, p. 57-76, 1999.

Pinker, S. Como a mente funciona. 2. ed. São Paulo: Companhia das Letras, 1999.

ORGANIZAÇÃO MUNDIAL DE SAÚDE (2005). Envelhecimento ativo: uma política de saúde. Tradução de Suzana Gontijo. Brasília: Organização Pan-Americana da Saúde. Disponível em: http://www. prosaude.org/publicacoes/diversos/envelhecimento_ativo.pdf Acesso em 02/06/2010.

Rabadán, O. J.: Lenguaje y envejecimiento. Bases para la intervención. Barcelona: Masson, 1998.

Rey, A. L'examen clinique en psychologie. Paris: Presses Universitaires de France, 1964.

Ska, B.; Fonseca, R. P.; Scherer, L. C.; Parente, M. A. M. P; Joanette, Y.. Mudanças no processamento cognitivo em adultos idosos: déficits ou estratégias adaptativas? In: Estudos Interdisciplinares sobre o Envelhecimento, 2009.

Sternberg, Robert J. Psicologia cognitiva. Porto Alegre: Artmed, 2000.

Spreen, O.; Strauss, E. A compendium of neuropsychological tests. Administration, norms, and commentary. Nova York: Oxford University Press, 1998.

Veríssimo, L. F. Catapultados (2008). Acessado em http://aeiou.expresso.pt/ catapultados $=\mathrm{f} 271830$. Acesso em maio de 2009.

[Recebido em 19/01/2012. Aprovado em 18/08/2012] 